\title{
Health-Related Quality of Life in Adolescents and Adults With Cystic Fibrosis: Physical and Mental Health Predictors
}

\author{
Jennifer A Cronly, Alistair J Duff, Kristin A Riekert, Anthony P Fitzgerald, Ivan J Perry, \\ Elaine A Lehane, Aine Horgan, Barbara A Howe, Muireann Ni Chroinin, and Eileen Savage
}

\begin{abstract}
BACKGROUND: People with cystic fibrosis face substantial physical, psychological, and social challenges as they move into adolescence and adulthood, which are likely to impact on their health-related quality of life. This study sought to examine the relative importance of physical and mental health variables associated with health-related quality of life in this group. METHODS: Adults and adolescents $(N=174 ; \geq 14$ y old $)$ from across 11 adult or pediatric cystic fibrosis clinics in the Republic of Ireland, completed a background questionnaire that contained self-reported physical health variables, pulmonary function (ie, $\mathrm{FEV}_{1} \%$ ) and body mass index. Questionnaire packs also contained the Hospital Anxiety and Depression Scale (HADS) and the Cystic Fibrosis Questionnaire-Revised, which has been specifically designed to assess health-related quality of life in patients with cystic fibrosis. RESULTS: HADS depression and/or anxiety scores were negatively associated with 11 of the 12 Cystic Fibrosis Questionnaire-Revised domain scores. FEV $\%$ was positively associated with 8 domains when controlling for HADS anxiety but only 4 domains when controlling for HADS depression. HADS anxiety and depression scores demonstrated larger effect sizes and explained a greater proportion of the variance than pulmonary function in 8 of the 12 Cystic Fibrosis Questionnaire-Revised domain scores. CONCLUSIONS: Mental health variables, depression and anxiety, were strongly associated with health-related quality of life in subjects with cystic fibrosis and demonstrated greater effect sizes and explained a higher proportion of the variance overall than the physical health indicators, $\mathrm{FEV}_{1} \%$ and body mass index, which highlighted the importance of screening for, and treating, depression and anxiety symptoms. Key words: anxiety; depression; cystic fibrosis; predictors; health-related quality of life (HRQOL); mental health; physical health. [Respir Care 2019;64(4):406-415. (C) 2019 Daedalus Enterprises]
\end{abstract}

\section{Introduction}

Adolescents and and adults living with cystic fibrosis have significant physical, psychological, and social chal-

\footnotetext{
Drs Savage, Cronly, Horgan, Lehane, and Ms Howe are affiliated with the School of Nursing and Midwifery in University College Cork, Cork, Republic of Ireland. Dr Duff is affiliated with the Department of Clinical Health Psychology in the Leeds Teaching Hospitals, NHS Trust, Leeds, United Kingdom. Dr Riekert is affiliated with the Johns Hopkins Adherence Research Center in the John Hopkins School of Medicine, Baltimore, Maryland. Drs Perry and Fitzgerald are affiliated with the School of Public Health in University College Cork, Cork, Republic of Ireland. Dr Ni Chroinin is affiliated with Department of Pediatrics in Cork University Hospital, Cork, Republic of Ireland.
}

The study was conducted through University College Cork, Cork, Republic of Ireland. lenges. ${ }^{1,2}$ Adolescence can be a particularly challenging developmental period due to rapid physical, psychological, and social changes, which may be accompanied by declining health, increasing treatment burden, and greater awareness of the potential negative consequences of the illness. ${ }^{3-5}$ As adolescents move into young adulthood, they

\footnotetext{
Funding was obtained from Cystic Fibrosis Ireland and the Health Research Board Ireland (grant file reference MRCG/2011/9).

The authors have disclosed no conflicts of interest.

Correspondence: Eileen Savage PhD, School of Nursing and Midwifery, Brookfield Health Sciences Complex, University College Cork, Western Road, Cork, Republic of Ireland. E-mail: e.savage@ucc.ie.
}

DOI: $10.4187 /$ respcare. 06356 
also face increasing social and psychological challenges, such as moving out of the family home, becoming more independent, forming intimate relationships, and entering third-level education or the employment sector. ${ }^{6,7}$ In addition, individuals with cystic fibrosis may face challenges associated with sexuality, fertility, and parenthood. ${ }^{5,7,8} \mathrm{Rec}-$ ognition of these challenges has led to an increasing focus on the importance of psychological and social functioning, and health-related quality of life (HRQOL) in both adolescents and adults with cystic fibrosis.

As a multidimensional concept, HRQOL refers to the impact of disease on holistic well-being as well as on physical, social, and psychological functioning. ${ }^{9,10}$ The patient's own perspective is valued, including the subjective experience of emotional well-being, the impact of symptoms on his or her life ability to participate in daily activities, social engagements, education, and employment, and relationships with others and the environment. ${ }^{11-13}$ Recognition of the importance of HRQOL in people with cystic fibrosis has led to a growing body of research and the development of a specific HRQOL instrument, the Cystic Fibrosis Questionnaire-Revised. ${ }^{14}$ In reflecting its multidimensional nature, this instrument measures HRQOL across 12 domains, including physical functioning, emotional functioning, social functioning, role, vitality, body image, eating, treatment burden, health perceptions, weight, respiratory symptoms, and digestive symptoms.

A systematic review of 23 studies examined the relationship between HRQOL in people with cystic fibrosis and demographic and physical health variables, including age, sex, socioeconomic status, employment status, pulmonary function (ie, $\mathrm{FEV}_{1} \%$ ), pulmonary exacerbations, and body mass index (BMI). ${ }^{15} \mathrm{FEV}_{1} \%$ and pulmonary exacerbations emerged as the strongest predictors of HRQOL, with studies consistently finding 9 of the 12 assessed domains positively associated with $\mathrm{FEV}_{1} \%$ and 8 of the 12 domains negatively associated with pulmonary exacerbations. BMI was significantly correlated with just 2 Cystic Fibrosis Questionnaire-Revised domains: body image and weight. Sex also emerged as significant, with males reporting higher scores in physical functioning and females reporting higher scores in body image. Age was negatively correlated with just 1 domain, treatment burden. Although indicators of physical health emerged as strong predictors of HRQOL, this systematic review did not examine the role of mental health variables. Few studies have examined the relationship between mental health indicators, such as depression and anxiety symptoms, and HRQOL in people with cystic fibrosis. Given that individuals with cystic fibrosis are at risk of depression and anxiety symptoms, ${ }^{16}$ it is important to investigate the impact these have on HRQOL.

A small number of studies investigated the associations between depression and anxiety, and HRQOL in people

\section{QUICK LOOK}

\section{Current knowledge}

Living with cystic fibrosis poses significant challenges, and people with cystic fibrosis are at risk of depression and anxiety symptoms. It is important to examine the variables associated with health-related quality of life in this population so that it can be strengthened and maintained. Physical health indicators, $\mathrm{FEV}_{1} \%$, and recent pulmonary exacerbations, have been linked to health-related quality of life in this population.

\section{What this paper contributes to our knowledge}

Anxiety and depression symptoms are significantly associated with health-related quality of life in people with cystic fibrosis. Analysis of our data indicated that anxiety and depression symptoms impacted health-related quality of life in its broadest sense, and affected physical, emotional, and social functioning. Mental health indicators demonstrated larger effect sizes and explained more of the variance than physical health indicators across a wide range of health-related qualityof-life domains.

with cystic fibrosis, which indicated that these symptoms are negatively associated with HRQOL in this population. ${ }^{2,17-19}$ Few studies used multivariate analysis to quantify the effects of depression and anxiety on HRQOL. One study, of 129 adults in a single United Kingdom cystic fibrosis center, showed depression and anxiety symptoms to be significant negative predictors of HRQOL, and explained the greater degree of variance than the physical health indictors, including $\mathrm{FEV}_{1} \%$, BMI, or recent hospitalizations. ${ }^{2}$ HRQOL is a multidimensional concept however, and this study did not examine the various domains of HRQOL including physical, social, or emotional functioning.

Another study found that, when controlling for $\mathrm{FEV}_{1} \%$, anxiety was a significant predictor of 6 HRQOL domains (vitality, emotional functioning, social functioning, treatment burden, health perceptions, and respiratory symptoms) and that depression was a significant predictor of 3 domains (emotional functioning, eating, and body image). ${ }^{19}$ However, this study did not examine the variance accounted for by physical and mental health variables. There is a dearth of studies that used multivariate methods to examine the relative contribution of both physical and mental health variables in predicting HRQOL across domains, which possibly led to confounding bias in reported findings. It is important to disentangle the effects of physical and mental health variables so that HRQOL can be 
optimized in patients with cystic fibrosis. The aim of this study was to examine the variables associated with HRQOL in adolescents and adults with cystic fibrosis with a focus on the relative importance of physical health indicators, $\mathrm{FEV}_{1} \%$ and BMI, and of the mental health variables, depression and anxiety symptoms.

\section{Methods}

\section{Study Design}

This study was part of a large, national, cross-sectional study on the prevalence of depression and anxiety in adolescents and adults with cystic fibrosis and their caregivers. This paper reported only on the data from adolescents and adults with cystic fibrosis and ages $\geq 14$ y. Ethical approval to conduct the study was granted by the relevant Clinical Research Ethics Committee (Ref ECM4[ii]04/12/12).

\section{Participants}

The sample of 174 adults and adolescents ages $\geq 14 \mathrm{y}$ with cystic fibrosis were recruited from 11 adult or pediatric cystic fibrosis centers across 9 hospitals in the Republic of Ireland. Inclusion criteria were a cystic fibrosis diagnosis by sweat test and age $\geq 14$ y old. Exclusion criterion was having received an organ transplantation. According to data published by the Cystic Fibrosis Registry of Ireland in 2014 (the year of data collection), there were 595 adults and 342 adolescents (12-18 y old), with cystic fibrosis registered as living in the Republic of Ireland. ${ }^{20}$ It was calculated that a sample size of 382 adults and 248 adolescents would be needed to estimate the prevalence rates of depression and anxiety to within $3 \%$ with 95\% confidence. However, due to challenges in recruitment, this sample size could not be attained. ${ }^{21}$ The sample size of 141 adults and 33 adolescents (14-18 y old) included in the HRQOL analysis represented $23.7 \%$ of the adult and $9.6 \%$ of the adolescent cystic fibrosis population in Ireland, respectively.

\section{Measures}

Questionnaire packs contained the following instruments: a background questionnaire, the Hospital Anxiety and Depression Scale (HADS), and the Cystic Fibrosis Questionnaire- Revised for adolescents and adults $\geq 14 \mathrm{y}$. The background questionnaire contained items on demographic and physical health variables, including self-reported height, weight, and $\mathrm{FEV}_{1} \%$ obtained from the most recent clinic appointment. The height and weight variables were used to calculate BMI. The HADS is a depression and anxiety screening tool suitable for use in community and hospital populations ${ }^{22}$ and has been validated for use in adolescents ages $>12 \mathrm{y} .{ }^{23}$ It contains 14 items: 7 depression and 7 anxiety. Both depression and anxiety scales score ranges are $0-21$. Established thresholds indicate elevated depression or anxiety symptoms for a score of $>7$ on either of the respective subscales. A score of $>10$ indicates clinically important symptoms of depression or anxiety. Previous research has indicated that the HADS has excellent internal consistency, test-retest reliability, discriminant validity, and factor structure. ${ }^{23,24}$

The Cystic Fibrosis Questionnaire-Revised is a valid and reliable measure of HRQOL in people with cystic fibrosis. ${ }^{14}$ The version developed for patients ages $\geq 14$ y has 50 items that are categorized under 9 HRQOL domains and 3 symptom domains. With regard to the multidimensional nature of HRQOL, the domains include the following: physical functioning, role, vitality, emotional functioning, social functioning, body image, eating, treatment burden, health perceptions, weight, respiratory symptoms, and digestive symptoms. Scaled scores for each of the domains range from 0 to 100; higher scores indicate higher HRQOL. The Cystic Fibrosis Questionnaire-Revised has strong psychometric properties with good internal validity, adequate reliability, and clinical sensitivity. $14,15,25$

\section{Procedure}

Adult patients were recruited during a routine clinic visit or online. However, adolescents were only recruited at clinic visits. Of the 174 participants, 94 were recruited from clinic settings and 80 were recruited online. In the clinics, the adults gave informed consent, and parental informed consent was required before the research team approached the adolescents. The participants had the option of completing the questionnaire in the clinic or later at home. Those who opted for the latter $(n=28)$ were provided with a stamped addressed envelope for return of the questionnaire to the research team. The overall response rate for recruitment in adult clinics was 51\%, and 39\% in pediatric clinics.

Challenges associated with access and data collection in clinics resulted in slow recruitment, and, consequently, the decision was made to also recruit online. ${ }^{21}$ An e-mail link to the questionnaire was sent by the charity Cystic Fibrosis Ireland to its community network of 345 adults with cystic fibrosis. The online version of the questionnaire was developed and administered by using the cloud-based software SurveyMonkey (at SurveyMonkey.com, San Mateo, California). Along with the link to the questionnaire, an online information sheet and a consent form were also included. A total of 99 online questionnaires were returned, although 19 were incomplete and not included for analyses. The 80 online responses represented $23 \%$ of the available population. 
Table 1. Demographic and Physical and Mental Health Variables

\begin{tabular}{lc}
\hline \multicolumn{1}{c}{ Variable } & Results \\
\hline Age, mean \pm SD y $(N=174)$ & $27.4 \pm 9.4$ \\
Sex, $n(\%)$ & $82(47.7)$ \\
$\quad$ Male & $90(52.3)$ \\
$\quad$ Female & \\
Physical health indicators, mean \pm SD & $69.0 \pm 24.8$ \\
$\quad$ FEV ${ }_{1} \%(n=122)$ & $21.5 \pm 2.7$ \\
BMI, $\mathrm{kg} / \mathrm{m}^{2}(n=119)$ & \\
Mental health indicators, mean \pm SD score & $5.6 \pm 4.0$ \\
$\quad$ HADS anxiety $(n=173)$ & $2.7 \pm 3.2$ \\
$\quad$ HADS depression $(n=173)$ & \\
\hline BMI $=$ body mass index & \\
HADS $=$ Hospital Anxiety and Depression Scale & \\
\hline
\end{tabular}

\section{Statistical Analysis}

Data were analyzed by using IBM SPSS 22.0 for Windows (IBM, Armonk, New York). Descriptive statistics were performed to describe participant demographics. To determine the predictors of Cystic Fibrosis QuestionnaireRevised domain scores, multiple linear regressions were conducted. For each multiple regression model, the Cystic Fibrosis Questionnaire-Revised domain score was entered as the dependent variable, and age, sex, $\mathrm{FEV}_{1} \% \mathrm{BMI}$, and either HADS anxiety or depression were entered as independent variables. Standardized coefficients were used as a measure of relative effect size, and squared part correlational coefficients were used to calculate the proportion of the variance explained by each predictor in the model. Depression and anxiety were not entered into the same model due to collinearity $(\mathrm{r}=0.62, P=.001)$.

\section{Results}

\section{Sample Demographics}

Participants $(N=174)$ ranged in age from 14 to $64 \mathrm{y}$ (mean \pm SD, $27.4 \pm 9.4$ y), of whom, 33 (19.2\%) were adolescents ages $14-18 \mathrm{y}$. Just over half of the sample $(52.3 \%[n=90])$ were female, and $47.7 \%(n=82)$ were male. All identified their nationality as Irish (Table 1). The mean \pm SD age of cystic fibrosis diagnosis was $3.9 \pm 8.6$ y. Consensus statements in $2004^{26}$ and $2005^{27}$ recommended neonatal screening programs for cystic fibrosis in every country. However, neonatal screening for cystic fibrosis consistent with best practice guidelines ${ }^{28}$ was not introduced into Ireland until 2011, ${ }^{29}$ and, before this, the diagnosis was based on clinical presentation and diagnostic sweat testing.

\section{Physical and Mental Health Indicators}

The mean $\pm \mathrm{SD}$ value for $\mathrm{FEV}_{1} \%$ was $69.0 \% \pm 24.8 \%$ of predicted $(n=122)$. Of the sample, $15.6 \%(n=19)$ had an $\mathrm{FEV}_{1} \%$ value of $<40 \%$, which was indicative of advanced pulmonary disease. ${ }^{28}$ The mean \pm SD value for BMI was $21.5 \pm 2.7 \mathrm{~kg} / \mathrm{m}^{2}(n=119)$, and $15.1 \%(n=18)$ had a BMI of $<19 \mathrm{~kg} / \mathrm{m}^{2}$, which is associated with increased risk of mortality in patients with cystic fibrosis. ${ }^{30}$ The mean \pm SD scores for HADS anxiety and depression were $5.6 \pm 4.0$ ) and $2.7 \pm 3.2$, respectively. Descriptive statistics for physical and mental health variables are presented in Table 1. In total, $26.0 \%$ of the participants $(n=45)$ had elevated anxiety symptom scores $(>7)$ and $12.7 \%$ $(n=22)$ had scores in the clinically important range $(>10)$. For depression, $8.1 \%(n=14)$ had elevated symptoms and $3.5 \%(n=6)$ had symptoms in the clinically important range.

\section{Predictors of HRQOL}

HADS anxiety was a significant negative predictor of 10 of the 12 Cystic Fibrosis Questionnaire-Revised domain scores. In the regression models, in which anxiety was included as a predictor, $\mathrm{FEV}_{1} \%$ was a significant positive predictor for 8 of the 12 domains. Age was not a significant predictor for any of the Cystic Fibrosis Questionnaire-Revised domains in these models. Sex was a significant predictor of body image and weight because being male was associated with lower scores in each of these domains. The values for these regression models, the effect sizes, and the proportion of the variance accounted for by each predictor are illustrated in Table 2 .

HADS depression was a significant negative predictor of 11 of the 12 Cystic Fibrosis Questionnaire-Revised domains. In the regression models in which depression was included as a predictor, $\mathrm{FEV}_{1} \%$ was a significant positive predictor of 4 of the 12 domains. BMI was a significant predictor of 2 domains in these regression models. Age was not a significant predictor of any of the domain scores, but sex was a significant predictor of weight, body image, and physical functioning because being male was associated with lower Cystic Fibrosis Questionnaire-Revised scores in weight and body image but higher scores in physical functioning. The values for these regression models, along with effect sizes and the proportion of the variance, accounted for by each predictor are presented in Table 3.

\section{Discussion}

In examining the associations between HRQOL and sociodemographic, physical, and mental health variables, this study highlighted the role of mental health in HRQOL in 
PREDICTORS OF HRQOL IN CYSTIC Fibrosis

Table 2. Multiple Linear Regressions With CFQ-R Domain Scores as Dependent Variables and With Age, Sex, FEV 1 \%, BMI, and HADS Anxiety as Independent Variables

\begin{tabular}{|c|c|c|c|c|c|c|}
\hline \multirow[t]{2}{*}{$\begin{array}{l}\text { Dependent Variable, } \\
\text { CFQ-R Domains }\end{array}$} & \multirow[t]{2}{*}{$\begin{array}{l}\text { Independent } \\
\text { Variable }\end{array}$} & \multicolumn{2}{|c|}{$\begin{array}{l}\text { Standardized } \\
\text { Coefficient }\end{array}$} & \multirow{2}{*}{$\begin{array}{c}\text { Part } \\
\text { Correlation } \\
\text { Coefficient }^{2}\end{array}$} & \multicolumn{2}{|c|}{$\begin{array}{l}\text { Regression } \\
\text { Model } \\
\text { Adjusted } \mathrm{R}^{2}\end{array}$} \\
\hline & & $\beta$ & $P$ & & $\%$ & $P$ \\
\hline \multirow[t]{6}{*}{ Physical functioning } & & & & & 52.3 & $<.001$ \\
\hline & Age & -0.08 & .29 & $<0.01$ & & \\
\hline & Sex & 0.12 & .09 & 0.01 & & \\
\hline & $\mathrm{FEV}_{1} \%$ & 0.49 & .001 & 0.19 & & \\
\hline & BMI & 0.12 & .14 & 0.01 & & \\
\hline & HADS anxiety & -0.34 & .001 & 0.10 & & \\
\hline \multirow[t]{6}{*}{ Role } & & & & & 21.0 & $<.001$ \\
\hline & Age & 0.12 & .24 & 0.01 & & \\
\hline & Sex & -0.09 & .36 & $<0.01$ & & \\
\hline & $\mathrm{FEV}_{1} \%$ & 0.32 & .002 & 0.08 & & \\
\hline & BMI & 0.06 & .52 & $<0.01$ & & \\
\hline & HADS anxiety & -0.31 & .002 & 0.09 & & \\
\hline \multirow[t]{6}{*}{ Vitality } & & & & & 23.4 & $<.001$ \\
\hline & Age & -0.08 & .42 & $<0.01$ & & \\
\hline & Sex & 0.06 & .50 & $<0.01$ & & \\
\hline & $\mathrm{FEV}_{1} \%$ & 0.21 & .037 & 0.04 & & \\
\hline & BMI & -0.03 & .73 & $<0.01$ & & \\
\hline & HADS anxiety & -0.39 & .001 & 0.14 & & \\
\hline \multirow[t]{6}{*}{ Emotional functioning } & & & & & 54.8 & $<.001$ \\
\hline & Age & -0.01 & .86 & $<0.01$ & & \\
\hline & Sex & 0.01 & .91 & $<0.01$ & & \\
\hline & $\mathrm{FEV}_{1} \%$ & 0.18 & .02 & 0.03 & & \\
\hline & BMI & 0.05 & .55 & $<0.01$ & & \\
\hline & HADS anxiety & -0.68 & .001 & 0.43 & & \\
\hline \multirow[t]{6}{*}{ Social functioning } & & & & & 11.9 & $<.001$ \\
\hline & Age & -0.03 & .81 & $<0.01$ & & \\
\hline & Sex & 0.01 & .94 & $<0.01$ & & \\
\hline & $\mathrm{FEV}_{1} \%$ & 0.28 & .011 & 0.06 & & \\
\hline & BMI & -0.01 & .93 & $<0.01$ & & \\
\hline & HADS anxiety & -0.22 & .03 & 0.05 & & \\
\hline \multirow[t]{6}{*}{ Body image } & & & & & 31.6 & $<.001$ \\
\hline & Age & -0.08 & .39 & $<0.01$ & & \\
\hline & Sex & -0.26 & .003 & 0.07 & & \\
\hline & $\mathrm{FEV}_{1} \%$ & 0.15 & .12 & 0.02 & & \\
\hline & BMI & 0.14 & .13 & 0.02 & & \\
\hline & HADS anxiety & -0.46 & .001 & 0.20 & & \\
\hline \multirow[t]{6}{*}{ Eating } & & & & & 20.5 & $<.001$ \\
\hline & Age & 0.04 & .72 & $<0.01$ & & \\
\hline & Sex & 0.03 & .73 & $<0.01$ & & \\
\hline & $\mathrm{FEV}_{1} \%$ & 0.13 & .20 & 0.04 & & \\
\hline & BMI & 0.22 & .03 & 0.05 & & \\
\hline & HADS anxiety & -0.36 & .001 & 0.12 & & \\
\hline \multirow[t]{6}{*}{ Treatment burden } & & & & & 13.9 & $<.001$ \\
\hline & Age & 0.03 & .80 & $<0.01$ & & \\
\hline & Sex & 0.01 & .91 & $<0.01$ & & \\
\hline & $\mathrm{FEV}_{1} \%$ & 0.36 & .001 & 0.11 & & \\
\hline & BMI & 0.05 & .64 & $<0.01$ & & \\
\hline & HADS anxiety & -0.15 & .15 & 0.02 & & \\
\hline
\end{tabular}


Table 2. Continued

\begin{tabular}{|c|c|c|c|c|c|c|}
\hline \multirow[t]{2}{*}{$\begin{array}{l}\text { Dependent Variable, } \\
\text { CFQ-R Domains }\end{array}$} & \multirow[t]{2}{*}{$\begin{array}{l}\text { Independent } \\
\text { Variable }\end{array}$} & \multicolumn{2}{|c|}{$\begin{array}{l}\text { Standardized } \\
\text { Coefficient }\end{array}$} & \multirow{2}{*}{$\begin{array}{c}\text { Part } \\
\text { Correlation } \\
\text { Coefficient }^{2}\end{array}$} & \multicolumn{2}{|c|}{$\begin{array}{l}\text { Regression } \\
\text { Model } \\
\text { Adjusted } \mathrm{R}^{2}\end{array}$} \\
\hline & & $\beta$ & $P$ & & $\%$ & $P$ \\
\hline \multirow[t]{6}{*}{ Health perceptions } & & & & & 54.6 & $<.001$ \\
\hline & Age & -0.10 & .21 & 0.01 & & \\
\hline & Sex & -0.06 & .37 & $<0.01$ & & \\
\hline & $\mathrm{FEV}_{1} \%$ & 0.51 & .001 & 0.21 & & \\
\hline & BMI & 0.06 & .40 & $<0.01$ & & \\
\hline & HADS anxiety & -0.39 & .001 & 0.14 & & \\
\hline \multirow[t]{6}{*}{ Weight } & & & & & 19.7 & $<.001$ \\
\hline & Age & -0.10 & .31 & 0.01 & & \\
\hline & Sex & -0.26 & .006 & 0.07 & & \\
\hline & $\mathrm{FEV}_{1} \%$ & 0.12 & .24 & 0.01 & & \\
\hline & BMI & 0.39 & .001 & 0.13 & & \\
\hline & HADS anxiety & -0.09 & .37 & 0.01 & & \\
\hline \multirow[t]{6}{*}{ Respiratory symptoms } & & & & & 32.0 & $<.001$ \\
\hline & Age & 0.01 & .90 & $<0.01$ & & \\
\hline & Sex & 0.05 & .56 & $<0.01$ & & \\
\hline & $\mathrm{FEV}_{1} \%$ & 0.47 & .001 & 0.18 & & \\
\hline & BMI & 0.09 & .35 & 0.01 & & \\
\hline & HADS anxiety & -0.22 & .01 & 0.05 & & \\
\hline \multirow[t]{6}{*}{ Digestive symptoms } & & & & & 20.4 & $<.001$ \\
\hline & Age & $<0.01$ & .98 & $<0.01$ & & \\
\hline & Sex & 0.06 & .53 & $<0.01$ & & \\
\hline & $\mathrm{FEV}_{1} \%$ & 0.11 & .08 & 0.01 & & \\
\hline & BMI & 0.04 & .70 & $<0.01$ & & \\
\hline & HADS anxiety & -0.44 & .001 & 0.18 & & \\
\hline \multicolumn{7}{|l|}{$\begin{array}{l}N=121 . \\
\text { CFQ-R = Cystic Fibrosis Quest } \\
\text { BMI = body mass index } \\
\text { HADS = Hospital Anxiety and }\end{array}$} \\
\hline
\end{tabular}

people with cystic fibrosis. Previous research identified associations between physical health variables, such as $\mathrm{FEV}_{1} \%$ and HRQOL, ${ }^{15}$ but the results of this study indicate that mental health variables, depression and anxiety, are more strongly associated with HRQOL than physical health indicators. Depression and anxiety symptoms are associated with all but 1 Cystic Fibrosis QuestionnaireRevised domain, with larger effect sizes and explaining more of the variance in 8 of the 12 HRQOL domain scores. Analysis of our data underlined the impact that depression and anxiety symptoms have on HRQOL in its broadest sense, which affect an individual's participation in social activities, education or employment, their sense of vitality, physical and emotional health, and how they experience eating and digestion. Therefore, managing anxiety and depression symptoms is important to maintaining overall wellbeing, and physical, social, and emotional functioning in patients with cystic fibrosis.

Depression and anxiety have distinct clinical features but frequently co-exist ${ }^{31}$ and were correlated in this sam- ple. This statistical correlation made it difficult to disentangle the distinctive contribution of each in predicting HRQOL. Nevertheless, the separate regression models indicated that both anxiety and depression symptoms were associated with HRQOL across a wide range of domains. Depression symptoms account for high proportions of the variance in social functioning, vitality, and role, which indicated that these symptoms had a strong impact on an individual's ability or desire to interact with peers and engage in daily activities, education, or work. Alternatively, anxiety symptoms accounted for a high degree of the variance in the domains of emotional functioning and body image, which indicated that anxiety may disrupt one's sense of confidence and well-being. Analysis of these results also indicated that co-morbidity of depression and anxiety symptoms is likely to have a more negative impact on HRQOL than each symptom alone.

The sociodemographic variables of age and sex were not strongly associated with HRQOL in this study. Previous research indicates that males have higher HRQOL 
PREDICTORS OF HRQOL IN CYSTIC Fibrosis

Table 3. Multiple Linear Regressions With CFQ-R Domain Scores as Dependent Variables and Age, Sex, FEV ${ }_{1} \%$, BMI, and HADS Depression as Independent Variables

\begin{tabular}{|c|c|c|c|c|c|c|}
\hline \multirow[t]{2}{*}{$\begin{array}{c}\text { Dependent Variable } \\
\text { CFQ-R Domains }\end{array}$} & \multirow[t]{2}{*}{$\begin{array}{l}\text { Independent } \\
\text { Variables }\end{array}$} & \multicolumn{2}{|c|}{$\begin{array}{c}\text { Standardized } \\
\text { Coefficient }\end{array}$} & \multirow[t]{2}{*}{$\begin{array}{c}\text { Part } \\
\text { Correlation } \\
\text { Coefficient }^{2}\end{array}$} & \multicolumn{2}{|c|}{$\begin{array}{l}\text { Regression } \\
\text { Model } \\
\text { Adjusted } \mathrm{R}^{2}\end{array}$} \\
\hline & & $\beta$ & $P$ & & $\%$ & $P$ \\
\hline \multirow[t]{6}{*}{ Physical functioning } & & & & & 52.7 & $<.001$ \\
\hline & Age & -0.06 & .44 & $<0.01$ & & \\
\hline & Sex & 0.15 & .040 & 0.02 & & \\
\hline & $\mathrm{FEV}_{1} \%$ & 0.42 & .001 & 0.13 & & \\
\hline & BMI & 0.13 & .10 & 0.01 & & \\
\hline & HADS depression & -0.37 & .001 & 0.11 & & \\
\hline \multirow[t]{6}{*}{ Role } & & & & & 35.7 & $<.001$ \\
\hline & Age & 0.16 & .09 & 0.02 & & \\
\hline & Sex & -0.07 & .81 & $<0.01$ & & \\
\hline & $\mathrm{FEV}_{1} \%$ & 0.18 & .069 & 0.02 & & \\
\hline & BMI & 0.08 & .36 & 0.01 & & \\
\hline & HADS depression & -0.53 & .001 & 0.23 & & \\
\hline \multirow{6}{*}{ Vitality } & & & & & 34.0 & $<.001$ \\
\hline & Age & -0.04 & .65 & $<0.01$ & & \\
\hline & Sex & 0.09 & .30 & 0.01 & & \\
\hline & $\mathrm{FEV}_{1} \%$ & 0.08 & .41 & 0.01 & & \\
\hline & BMI & -.02 & .87 & $<0.01$ & & \\
\hline & HADS depression & -0.55 & .001 & 0.24 & & \\
\hline \multirow[t]{6}{*}{ Emotional functioning } & & & & & 51.1 & $<.001$ \\
\hline & Age & 0.03 & .72 & $<0.01$ & & \\
\hline & Sex & 0.06 & .41 & $<0.01$ & & \\
\hline & $\mathrm{FEV}_{1} \%$ & 0.06 & .52 & $<0.01$ & & \\
\hline & BMI & 0.07 & .35 & $<0.01$ & & \\
\hline & HADS depression & -0.70 & .001 & 0.39 & & \\
\hline \multirow[t]{6}{*}{ Social functioning } & & & & & 27.8 & $<.001$ \\
\hline & Age & 0.01 & .88 & $<0.01$ & & \\
\hline & Sex & 0.02 & .82 & $<0.01$ & & \\
\hline & $\mathrm{FEV}_{1} \%$ & 0.13 & .21 & 0.01 & & \\
\hline & BMI & 0.01 & .95 & $<0.01$ & & \\
\hline & HADS depression & -0.50 & .001 & 0.20 & & \\
\hline \multirow[t]{6}{*}{ Body image } & & & & & 28.3 & $<.001$ \\
\hline & Age & -0.05 & .58 & $<0.01$ & & \\
\hline & Sex & -0.23 & .01 & 0.05 & & \\
\hline & $\mathrm{FEV}_{1} \%$ & 0.07 & .48 & $<0.01$ & & \\
\hline & BMI & 0.16 & .10 & 0.02 & & \\
\hline & HADS depression & -0.46 & .001 & 0.17 & & \\
\hline \multirow[t]{6}{*}{ Eating } & & & & & 29.5 & $<.001$ \\
\hline & Age & 0.07 & .45 & $<0.01$ & & \\
\hline & Sex & 0.06 & .52 & $<0.01$ & & \\
\hline & $\mathrm{FEV}_{1} \%$ & 0.01 & .90 & $<0.01$ & & \\
\hline & BMI & 0.24 & .01 & 0.05 & & \\
\hline & HADS depression & -0.50 & .001 & 0.20 & & \\
\hline \multirow[t]{6}{*}{ Treatment burden } & & & & & 17.3 & $<.001$ \\
\hline & Age & 0.05 & .66 & $<0.01$ & & \\
\hline & Sex & 0.02 & .83 & $<0.01$ & & \\
\hline & $\mathrm{FEV}_{1} \%$ & 0.29 & .01 & 0.06 & & \\
\hline & BMI & 0.06 & .56 & $<0.01$ & & \\
\hline & HADS depression & -0.26 & .02 & 0.05 & & \\
\hline
\end{tabular}


PRedictors of HRQOL In Cystic Fibrosis

Table 3. Continued

\begin{tabular}{|c|c|c|c|c|c|c|}
\hline \multirow[t]{2}{*}{$\begin{array}{l}\text { Dependent Variable } \\
\text { CFQ-R Domains }\end{array}$} & \multirow[t]{2}{*}{$\begin{array}{l}\text { Independent } \\
\text { Variables }\end{array}$} & \multicolumn{2}{|c|}{$\begin{array}{l}\text { Standardized } \\
\text { Coefficient }\end{array}$} & \multirow{2}{*}{$\begin{array}{c}\text { Part } \\
\text { Correlation } \\
\text { Coefficient }^{2}\end{array}$} & \multicolumn{2}{|c|}{$\begin{array}{l}\text { Regression } \\
\text { Model } \\
\text { Adjusted } \mathrm{R}^{2}\end{array}$} \\
\hline & & $\beta$ & $P$ & & $\%$ & $P$ \\
\hline \multirow[t]{6}{*}{ Health perceptions } & & & & & 60.0 & $<.001$ \\
\hline & Age & -0.07 & .37 & $<0.01$ & & \\
\hline & Sex & -0.04 & .59 & $<0.01$ & & \\
\hline & $\mathrm{FEV}_{1} \%$ & 0.41 & .001 & 0.12 & & \\
\hline & BMI & 0.08 & .26 & 0.01 & & \\
\hline & HADS depression & -0.49 & .001 & 0.19 & & \\
\hline \multirow[t]{6}{*}{ Weight } & & & & & 20.1 & $<.001$ \\
\hline & Age & -0.10 & .35 & 0.01 & & \\
\hline & Sex & -0.26 & .007 & 0.06 & & \\
\hline & $\mathrm{FEV}_{1} \%$ & 0.09 & .39 & 0.01 & & \\
\hline & BMI & 0.39 & .001 & 0.13 & & \\
\hline & HADS depression & -0.12 & .26 & 0.01 & & \\
\hline \multirow[t]{6}{*}{ Respiratory symptoms } & & & & & 31.5 & $<.001$ \\
\hline & Age & 0.03 & .79 & $<0.01$ & & \\
\hline & Sex & 0.07 & .43 & $<0.01$ & & \\
\hline & $\mathrm{FEV}_{1} \%$ & 0.43 & .001 & 0.13 & & \\
\hline & BMI & 0.10 & .30 & 0.01 & & \\
\hline & HADS depression & -0.23 & .02 & 0.04 & & \\
\hline \multirow[t]{6}{*}{ Digestive symptoms } & & & & & 25.6 & $<.001$ \\
\hline & Age & 0.04 & .70 & $<0.01$ & & \\
\hline & Sex & 0.09 & .32 & 0.01 & & \\
\hline & $\mathrm{FEV}_{1} \%$ & -0.003 & .98 & $<0.01$ & & \\
\hline & BMI & 0.06 & .55 & $<0.01$ & & \\
\hline & HADS depression & -0.53 & .001 & 0.23 & & \\
\hline \multicolumn{7}{|c|}{$\begin{array}{l}n=121 . \\
\text { CFQ- } R=\text { Cystic Fibrosis Questionnaire-Revised } \\
\text { HADS = Hospital Anxiety and Depression Scale } \\
\text { BMI = body mass index }\end{array}$} \\
\hline
\end{tabular}

overall than females, ${ }^{32}$ but multivariate analysis in this study revealed that, when physical and mental health indicators are taken into account, being male is positively associated with just 1 domain, physical functioning. Being female is associated with higher scores in the domains of body image and weight. Previous work indicated that a lower BMI may have a more negative impact on HRQOL in males with cystic fibrosis because they may wish to be more muscular and robust compared with females with cystic fibrosis, for whom a lower BMI is considered desirable. ${ }^{32}$ Females with cystic fibrosis were reported to be more content with their body shape and weight than healthy controls, ${ }^{33}$ but lower BMI is associated with lower $\mathrm{FEV}_{1} \%$ in both males and females and, therefore, is a cause of concern. ${ }^{34}$ Nevertheless, the effect sizes and proportions of the variance accounted for by age and sex were very small in our study, which indicate that physical and mental health indicators play a more important role in predicting HRQOL.

Physical health was significantly associated with HRQOL in our study because $\mathrm{FEV}_{1} \%$ was associated with a wide range of domains, including physical function and vitality but also social functioning and role. These results indicated that poorer lung function may hinder an individual's ability to interact with peers and participate in daily activities. However, when the effects of depression are controlled, $\mathrm{FEV}_{1} \%$ explains little of the variance in the domains of role, vitality, or social and emotional functioning. Therefore, this study provided evidence that, although poor or declining physical health can have a negative impact on the multifaceted aspects of HRQOL, depression symptoms mediate this effect and play a greater role in predicting the variance across most domains.

When interpreting the results of our study, some limitations must be taken into consideration. First, the study adopted 2 recruitment processes for adults, in clinics and online, and the response rate for the online sample was low, at $23 \%$, mainly because of a shorter timeline of data collection compared with paper-based data collection. This was not necessarily indicative of nonresponse 
bias, however, and the results may still accurately represent the population. ${ }^{35}$ Although data from nonresponders were not available for comparison, data analysis conducted on the online and clinic samples yielded comparable findings. ${ }^{21}$

Second, the physical health predictors used, $\mathrm{FEV}_{1} \%$ and BMI, were self-reported, and cross-checking with medical notes was not feasible due to resource constraints. In addition, these predictors may not have fully captured physical health status for all the participants because previous studies have indicated recent pulmonary exacerbations may also predict HRQOL in people with cystic fibrosis. ${ }^{15}$ Data collection was cross-sectional. Longitudinal data on physical health indicators are needed to determine the impact of deterioration on various domains of HRQOL over time. Furthermore, due to collinearity between depression and anxiety, the regression models had to be run separately and so the unique contribution of depression and anxiety could not be extrapolated from each other.

The strengths of our study were that it provided a detailed exploration of the impact that depression and anxiety symptoms have on HRQOL in patients with cystic fibrosis. In addition, multivariate analysis was used to control for $\mathrm{FEV}_{1} \%$, age, and sex, which ensured that the contribution of depression and anxiety to HRQOL within each of the Cystic Fibrosis Questionnaire-Revised domains could be assessed. The results illustrated that a high degree of the variance for each domain was explained by the combined effects of the dependent variables entered into the model.

\section{Conclusions}

Adults and adolescents with cystic fibrosis face numerous challenges associated with their illness and must be supported to ensure that HRQOL is maintained throughout their life span despite physical health challenges. ${ }^{36}$ The findings of our study highlight the importance of patients' mental health in this regard because this has a greater impact than physical health in determining many aspects of HRQOL. For this reason, it is crucial that, as physical health declines, mental health is prioritized and maintained so that patients with cystic fibrosis can continue to have the highest HRQOL possible. The findings highlighted the importance of screening for and treating depression and anxiety symptoms.

\section{REFERENCES}

1. de Jong W, Kaptein AA, Van der Schaus CP, Mannes GP, van Aalderen WM, Gevink RG, Koëter GH. Quality of life in patients with cystic fibrosis. Pediatr Pulmonol 1997;23(2):95-100.

2. Yohannes AM, Willgoss TG, Fatoye FA, Dip DM, Webb K. Relationship between anxiety, depression, and quality of life in adult patients with cystic fibrosis. Respir Care 2012;57(4):550-556.
3. Ernst MM, Johnson MC, Stark LJ. Developmental and psychosocial issues in CF. Child Adolesc Psychiatr Clin N Am 2010;19(2):263283, viii.

4. Boyle IR, di SantAgnese PA, Sack S, Millican F, Kulczycki LL. Emotional adjustment of adolescents and young adults with cystic fibrosis. J Pediatr 1976;88(2):318-326.

5. Johannesson M, Carlson M, Brucefors AB, Hjelte L. Cystic fibrosis through a female perspective: psychosocial issues and information concerning puberty and motherhood. Patient Educ Couns 1998;34(2): 115-123.

6. Edwards J, Boxall K. Adults with cystic fibrosis and barriers to employment. Disabil Societ 2010;25(4):441-453.

7. Pfeffer PE, Pfeffer JM, Hodson ME. The psychosocial and psychiatric side of cystic fibrosis in adolescents and adults. J Cyst Fibros 2003;2(2):61-68.

8. Sawyer S. Reproductive and sexual health in adolescents with cystic fibrosis. BMJ 1996;313(7065):1095-1096.

9. Fontaine KR, Barofsky I. Obesity and health-related quality of life. Obes Rev 2001;2(3):173-182.

10. Rosenbaum PL, Livingston MH, Palisano RJ, Galuppi BE, Russell DJ. Quality of life and health-related quality of life of adolescents with cerebral palsy. Dev Med Child Neurol 2007;49(7):516-521.

11. Andresen EM, Meyers AR. Health-related quality of life outcomes measures. Arch Phys Med Rehabil 2000;81(12 Suppl 2):S30-S45.

12. Szyndler JE, Towns SJ, van Asperen PP, McKay KO. Psychological and family functioning and quality of life in adolescents with cystic fibrosis. J Cyst Fibros 2005;4(2):135-144.

13. Quittner A. Measurement of quality of life in cystic fibrosis. Curr Opin Pulm Med 1998;4(6):326-331.

14. Quittner AL, Buu A, Messer MA, Modi AC, Watrous M. Development and validation of The Cystic Fibrosis Questionnaire in the United States: a health-related quality of life measure for cystic fibrosis. Chest 2005;128(4):2347-2354.

15. Habib AR, Manji J, Wilcox PG, Javer AR, Buxton JA, Quon BS. A systematic review of factors associated with health-related quality of life in adolescents and adults with cystic fibrosis. Ann Am Thorac Soc 2015;12(3):420-428.

16. Quittner AL, Goldbeck L, Abbott J, Duff A, Lambrecht P, Solé A, et al. Prevalence of depression and anxiety in patients with cystic fibrosis and parent caregivers: results of the international depression epidemiological study across nine countries. Thorax 2014;69(12): 1090-1097.

17. Riekert KA, Bartlett SJ, Boyle MP, Krishnan JA, Rand CS. The association between depression, lung function, and health-related quality of life among adults with cystic fibrosis. Chest 2007;132(1): 231-237.

18. Olveira C, Sole A, Girón RM, Quintana-Gallego E, Mondejar P, Baranda F, et al. Depression and anxiety symptoms in Spanish adult patients with cystic fibrosis: associations with health-related quality of life. Gen Hosp Psychiatry 2016;40:39-46.

19. Havermans T, Colpaert K, Dupont L. Quality of life in patients with cystic fibrosis: association with anxiety and depression. J Cyst Fibros 2008;7(6):581-584.

20. Cystic Fibrosis Registry of Ireland. Annual Report 2012. Dublin: Cystic Fibrosis Registry of Ireland; 2014.

21. Cronly J, Duff AJ, Riekert KA, Perry IJ, Fitzgerald AP, Horgan A, et al. Online versus paper-based screening for depression and anxiety in adults with cystic fibrosis in Ireland: a cross-sectional exploratory study. BMJ Open 2018;8(1):e019305.

22. Zigmond AS, Snaith RP. The hospital anxiety and depression scale. Acta Psychiatr Scand 1983;67(6):361-370.

23. White D, Leach C, Sims R, Atkinson M, Cottrell D. Validation of the Hospital Anxiety and Depression Scale for use with adolescents. Br J Psychiatry 1999;175:452-454. 
24. Bjelland I, Dahl AA, Haug TT, Neckelmann D. The validity of the hospital anxiety and depression scale: an updated literature review. J Psychosom Res 2002;52(2):69-77.

25. Quittner AL, Sawicki GS, McMullen A, Rasouliyan L, Pasta DJ, Yegin A, Konstan MW. Erratum to: Psychometric evaluation of the Cystic Fibrosis Questionnaire-Revised in a national, US sample. Qual Life Res 2012;21(7):1279-1290.

26. Döring G, Hoiby N; Consensus Study Group. Early intervention and prevention of lung disease in cystic fibrosis: a European consensus. J Cyst Fibros 2004;3(2):67-91.

27. Kerem E, Conway S, Elborn S, Heijerman H; Concensus Committee. Standards of care for patients with cystic fibrosis: a European consensus. J Cyst Fibros 2005;4(1):7-26.

28. Castellani C, Duff AJA, Bell SC, Heijerman HGM, Munck A, Ratjen F. ECFS best practice guidelines: the 2018 revision. J Cyst Fibros 2018;17(2):153-178.

29. Fitzgerald C, Linnane B, Heery E, Conneally N, George S, Fitzpatrick P. Newborn bloodspot screening for cystic fibrosis: what do antenatal and postnatal women know about cystic fibrosis? J Cyst Fibros 2016;15(4):436-442.

30. George PM, Banya W, Pareek N, Bilton D, Cullinan P, Hodson ME, Simmonds NJ. Improved survival at low lung function in cystic fibrosis: cohort study from 1990 to 2007. BMJ 2011;342:d1008.
31. Hirschfeld R. The comorbidity of major depression and anxiety disorders: recognition and management in primary care. Prim Care Companion J Clin Psychiatry 2001;3(6):244-254

32. Gee L, Abbott J, Conway SP, Etherington C, Webb AK. Quality of life in cystic fibrosis: the impact of gender, general health perceptions and disease severity. J Cyst Fibros 2003;2(4):206213.

33. Abbott J, Conway S, Etherington C, Fitzjohn J, Gee L, Morton A, et al. Perceived body image and eating behaviour in young adults with cystic fibrosis and their healthy peers. J Behav Med 2000;23(6):501517.

34. Sheikh S, Zemel BS, Stallings VA, Rubenstein RC, Kelly A. Body composition and pulmonary function in cystic fibrosis. Front Pediatr 2014;2:33.

35. Meterko M, Restuccia J, Stolzmann K, Mohr D, Brennan C, Glasgow J, et al. Response rates, nonresponse bias, and data quality: results from a national survey of senior healthcare leaders. Public Opin Q 2015;79(1):130-144.

36. Mc Hugh R, Mc Feeters D, Boyda D, O’Neill S. Coping styles in adults with cystic fibrosis: implications for emotional and social quality of life. Psychol Health Med 2016;21(1):102112. 